\title{
CFD Modeling and Simulation of Hydrodynamics in a Fluidized Bed Dryer with Experimental Validation
}

\author{
Mahdi Hamzehei \\ Department of Mechanical Engineering, Islamic Azad University, Ahvaz Branch, Ahvaz 37333-61349, Iran \\ Correspondence should be addressed to Mahdi Hamzehei, mahdi_hamzei@aut.ac.ir
}

Received 15 January 2011; Accepted 7 March 2011

Academic Editors: H.-T. Low and A. Z. Sahin

Copyright () 2011 Mahdi Hamzehei. This is an open access article distributed under the Creative Commons Attribution License, which permits unrestricted use, distribution, and reproduction in any medium, provided the original work is properly cited.

Gas-solid fluidized bed dryers are used in a wide range of industrial applications. With applying computational fluid dynamic (CFD) techniques, hydrodynamics of a two-dimensional nonreactive gas-solid fluidized bed dryer was investigated. A multifluid Eulerian model incorporating the kinetic theory for solid particles was applied to simulate the unsteady state behavior of this dryer and momentum exchange coefficients were calculated by using the Syamlal-O'Brien drag functions. A suitable numerical method that employed finite volume method was used to discretize the equations. Simulation results also indicated that small bubbles were produced at the bottom of the bed. These bubbles collided with each other as they moved upwards forming larger bubbles. Also, solid particles diameter and superficial gas velocity effect on hydrodynamics were studied. Simulation results were compared with the experimental data in order to validate the CFD model. Pressure drops and bed expansion ratio as well as the qualitative gas-solid flow patterns predicted by the simulations were in good agreement with experimental measurements at superficial gas velocities higher than the minimum fluidization velocity. Furthermore, this comparison showed that the model can predict hydrodynamic behavior of gas solid fluidized bed reasonably well.

\section{Introduction}

Fluidized bed dryers are found in a wide range of applications in various industrial operations, including chemical, petroleum, mineral, and pharmaceutical industries. Understanding the hydrodynamics of fluidized-bed dryers is essential for choosing the correct operating parameters for the appropriate fluidization regime [1-3]. The fundamental problem encountered in modeling hydrodynamics of a gassolid fluidized bed is the motion of two phases where the interface is unknown and transient, and the interaction is understood only for a limited range of conditions $[1,2]$.

Computational fluid dynamics (CFDs) is becoming more and more an engineering tool to predict flows in various types of apparatus on industrial scale. Although the tools for applying single-phase flow CFD are widely available, application of multiphase CFD is, however, still complicated from both a physical and a numerical point of view. Moreover, experimental validation of multiphase CFD models is still in its infancy because simulations are time consuming and reliable predictions of average flows in large scale equipment are therefore not readily obtained $[3,4]$.

The Eulerian-Lagrangian and Eulerian-Eulerian models have been applied to the CFD modeling of multiphase systems. For gas-solid flows modeling, usually, EulerianLagrangian models are called discrete particle models and Eulerian-Eulerian models are called granular flow models. Granular flow models (GFMs) are continuum based and are more suitable for simulating large and complex industrial fluidized-bed dryers containing billions of solid particles. In principle, discrete particle models (DPMs) in turn need closure laws to model fluid-particle interactions and particleparticle interaction parameters based on contact theory and material properties. Direct solution of Navier-Stokes equations is too computation intensive to simulate even thousands of solid particles rather than millions of particles [3-5].

The Lagrangian model solves the Newtonian equations of motion for each individual particle in the gas-solid system along with a collision model to handle the energy 
dissipation caused by nonideal particle-particle interactions. The large number of equations involved makes this model a very time-consuming computational method for simulating fluidized beds of high particle concentration $[3,4]$. The Eulerian model treats all different phases mathematically as continuous and fully interpenetrating. Generalized NavierStokes equations are employed for the interacting continua. The highly reduced number of equations solved during each iteration generates a timesaving advantage in comparison to the Lagrangian model. Modeling of the hydrodynamics of gas-solid multiphase systems with Eulerian models using different CFD codes has shown the suitability of this approach for fluidized bed modeling $[1,3,6,7]$.

The kinetic theory of granular flow proposes a granular temperature that is proportional to the kinetic energy of the fluctuating component of the particles velocity. To model solid particles as a separate fluid phase, physical parameters such as the solids pressure and viscosity can be obtained from granular theory $[2,3,5,8]$.

Goldschmidt et al. [6] compared a hard-sphere discrete particle model with a two-fluid model containing kinetic theory closure equations using appropriate experimental data. Their results indicate that both CFD models predict adequate fluidization regimes and trends in bubble sizes and bed expansion, whereas predicted bed expansion dynamics differs significantly from the experimental results. Taghipour et al. [7] and kaneko et al. [9] have conducted experimental and computational studies of gas-solid fluidized-bed dryer hydrodynamics. CFD simulation results were compared to those obtained from the experiments. Comparison of the model predictions, using the Syamlal-O'Brien, Gidaspow, and Wen-Yu drag functions and experimental measurements on the time-average bed pressure drop, bed expansion, and qualitative gas-solid flow pattern indicated reasonable agreement for most operating conditions.

Behjat et al. [10, 11] investigated unsteady-state behavior of gas-solid fluidized beds. They showed that model predictions of bubble size and gas-solid flow pattern using both Syamlal-O'Brien and Gidaspow drag models were similar. Huilin et al. [12, 13] studied bubbling fluidized bed with the binary mixtures applying multifluid Eulerian CFD model according to the kinetic theory of granular flow. Their simulation results showed that hydrodynamics of gas bubbling fluidized bed is related with the distribution of particle sizes and the amount of dissipated energy in particleparticle interactions.

Gobin et al. [14] numerically simulated a fluidized bed using two-phase flow method. Van Wachem et al. [15-17] attempted to verify experimentally Eulerian-Eulerian gassolid model simulations of bubbling fluidized beds with existing correlations for bubble size or bubble velocity. CFD model for a free bubbling fluidized bed was implemented in the commercial code CFX of AEA Technology. Chiesa et al. [18] have presented a computational study of the flow behavior of a lab-scale fluidized bed. They have also compared experiment results of a two-dimensional lab-scale bubbling fluidized bed with their computational results. The results showed that, when Eulerian and Lagrangian approaches were applied, the numerical simulations led to a rather similar pattern with the experimental data.

Hamzehei et al. [19-22] investigated unsteady flow and heat transfer in a gas-solid fluidized-bed reactor. Also particle sizes, gas velocity, and drag models effects on hydrodynamics and heat transfer of a nonreactive gas-solid fluidized bed reactor were studied experimentally and computationally. The Eulerian-Eulerian model with the standard $k-\varepsilon$ turbulence model was used for modeling the fluidized bed reactor. In order to validate the model, an experimental setup was fabricated and a series of tests were performed. The predicted time-average bed expansion ratio, pressure drop, and cross-sectional voidage profiles using Cao-Ahmadi, Syamlal-O'Brien, and Gidaspow drag models were compared with corresponding values of experimentally measured data. The modeling predictions compared reasonably well with the experimental bed expansion ratio measurements and qualitative gas-solid flow patterns. Pressure drops predicted by the simulations were in relatively close agreement with the experimental measurements for superficial gas velocities higher than the minimum fluidization velocity. Results show that there is no significant difference for different drag models, so the results suggest that all three drag models are more suitable for predicting the hydrodynamics of gas-solid flows.

Despite many studies on the modeling and model evaluation of fluidized bed hydrodynamics, only a few works have been published on the CFD modeling and model validation of combined dryer hydrodynamics. Also, only a limited number of works have been reported on the successful CFD modeling of fluidized bed hydrodynamics at different conditions. In this research, the hydrodynamics of two-dimensional nonreactive gas-solid fluidized bed dryer was investigated computationally and experimentally. Also, solid particles diameter and superficial gas velocity effects on hydrodynamics were studied. A multifluid Eulerian model incorporating the kinetic theory for solid particles was applied in order to simulate the gas-solid flow at different superficial gas velocities with different particle sizes. Simulation results were compared with the experimental data for model validation.

\section{Experimental Setup}

Experiments were conducted in a Plexiglas cylinder with $100 \mathrm{~cm}$ height and $28 \mathrm{~cm}$ diameter (Figure 1). The distributor consisted of a perforated plate of open area ratio $0.8 \%$. Spherical glass particles of 175,275 , and $375 \mu \mathrm{m}$ diameter and density $1883 \mathrm{~kg} / \mathrm{m}^{3}$ were fluidized with air at ambient conditions. A Roots-type blower supplied the fluidizing gas. A pressure-reducing valve was installed to avoid pressure oscillations and achieve a steady gas flow. The gas flow rates were measured by a flow meter. Pressure fluctuations in the bed were obtained by three pressure transducers. The pressure probes were used to convert fluctuation pressure signals to output voltage values proportional to the pressure. The output signal was amplified, digitized, and further processed on line using a dynamic signal analyzer. The ratio 


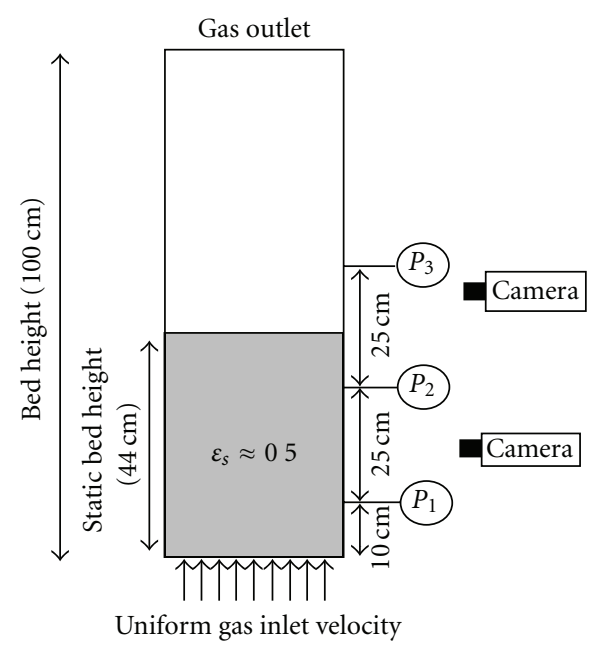

Figure 1: Schematic drawing of 2D fluidized bed dryer with pressure transducers position.

of the distributor pressure drop to the bed pressure drop exceeded $11 \%$ for all operating conditions investigated. The static bed height was $44 \mathrm{~cm}$ with a solids volume fraction of 0.5 . The overall pressure drop and bed expansion were monitored at different superficial gas velocities from 0 to $1 \mathrm{~m} / \mathrm{s}$. A digital camera (Canon 5000) and a digital video recorder (Sony DCR-PC330E) were employed to photograph the flow regimes and bed expansion at different conditions through the transparent wall during the experiments.

\section{Computational Model}

3.1. Governing Equations. The governing equations of the system include the conservation of mass and momentum. Equations of solid and gas phases were developed based on Eulerian-Eulerian model, using the averaging approach. The kinetic theory of granular flow, which considers the conservation of solid fluctuation energy, was used for closure of the solids stress terms. The governing equations can be summarized as follows.

By definition, the volume fractions of the phases must sum to one:

$$
\varepsilon_{g}+\varepsilon_{s}=1 .
$$

The continuity equations for gas and solid phases without mass transfer between the phases, respectively, are

$$
\begin{gathered}
\frac{\partial}{\partial t}\left(\varepsilon_{g} \rho_{g}\right)+\nabla \cdot\left(\varepsilon_{g} \rho_{g} \overrightarrow{v_{g}}\right)=0, \\
\frac{\partial}{\partial t}\left(\varepsilon_{s} \rho_{s}\right)+\nabla \cdot\left(\varepsilon_{s} \rho_{s} \overrightarrow{v_{s}}\right)=0 .
\end{gathered}
$$

The conservation of momentum for the gas phase and solid phase is described by

$$
\begin{aligned}
& \frac{\partial}{\partial t}\left(\varepsilon_{g} \rho_{g} \vec{v}_{g}\right)+\nabla \cdot\left(\varepsilon_{g} \rho_{g} \vec{v}_{g} \vec{v}_{g}\right) \\
& =-\varepsilon_{g} \nabla p_{g}+\nabla \cdot \overline{\overline{\tau_{g}}}+\varepsilon_{g} \rho_{g} \vec{g}+\beta_{g s}\left(\vec{v}_{g}-\vec{v}_{s}\right),
\end{aligned}
$$

$$
\begin{aligned}
& \frac{\partial}{\partial t}\left(\varepsilon_{s} \rho_{s} \vec{v}_{s}\right)+\nabla \cdot\left(\varepsilon_{s} \rho_{s} \vec{v}_{s} \vec{v}_{s}\right) \\
& \quad=-\varepsilon_{s} \nabla p_{g}-\nabla p_{s}+\nabla \cdot \overline{\bar{\tau}_{s}}+\varepsilon_{s} \rho_{s} \vec{g}+\beta_{g s}\left(\vec{v}_{s}-\vec{v}_{g}\right),
\end{aligned}
$$

where $\overline{\bar{\tau}}$ is Reynolds stress tensor, $g$ is gravitational constant, and $\left(-\varepsilon_{s} \nabla p+\beta_{g s}\left(\vec{v}_{g}-\vec{v}_{s}\right)\right)$ is an interaction force (drag and buoyancy forces) representing the momentum transfer between gas and solid phases [7, 9, 21-24]. The interphase momentum transfer is an important term in the modeling of gas-particle interactions, since particle fluidization results from the drag exerted by the interstitial gas on the particulate phase. Several drag models exist for the gas-solid interphase exchange coefficient $\left(\beta_{g s}\right)$. Syamlal-O'Brien drag function gives a somewhat better prediction when compared with the other models, and it is more suitable for predicting the hydrodynamics of gas-solid flows [7,9].

This drag law is based on the measurements of the terminal velocities of particles in fluidized or settling beds [23, 24]. These correlations give exchange coefficients in terms of the volume fraction and relative Reynolds number as

$$
\begin{gathered}
\beta_{g s}=\frac{3}{4} \frac{\varepsilon_{s} \varepsilon_{g} \rho_{g}}{v_{r, s}^{2} d_{s}} C_{D}\left(\frac{\mathrm{Re}_{s}}{v_{r, s}}\right)\left|\vec{v}_{s}-\vec{v}_{g}\right|, \\
C_{D}=\left(0.63+\frac{4.8}{\sqrt{\mathrm{Re}_{s} / v_{r, s}}}\right)^{2} .
\end{gathered}
$$

And $v_{r, s}$, a terminal velocity correlation, is expressed as

$$
\begin{aligned}
& v_{r, s} \\
& =0.5\left(A-0.06 \operatorname{Re}_{s}+\sqrt{\left(0.06 \operatorname{Re}_{s}\right)^{2}+0.12 \operatorname{Re}_{s}(2 B-A)+A^{2}}\right)
\end{aligned}
$$

with $A=\varepsilon_{g}^{4.14}$ and $B=0.8 \varepsilon_{g}^{1.28}$ for $\varepsilon_{g} \leq 0.85$ and $B=\varepsilon_{g}^{2.65}$ for $\varepsilon_{g}>0.85$ and $\operatorname{Re}_{s}$ is solids Reynolds number.

Following Gidaspow [1] it is assumed that the gas and solid phases are Newtonian fluids. Therefore the gas and solid phase viscous stresses are given by the following expression:

$$
\overline{\overline{\tau_{s, g}}}=\varepsilon_{s, g} \mu_{s, g}\left[\nabla \overrightarrow{v_{s, g}}+\left(\nabla \overrightarrow{v_{s, g}}\right)^{T}\right]+\varepsilon_{s, g}\left(\lambda_{s, g}-\frac{2}{3} \mu_{s, g}\right) \nabla \overrightarrow{v_{s, g}} \overline{\bar{I}} .
$$

The solids bulk viscosity accounts for the resistance of the granular particles to compression and expansion. It is obvious that the importance of the bulk viscosity depends strongly on the velocity gradients. In a fluidized bed the bulk viscosity should not be neglected, as is done in simulating Newtonian fluids. It has the following from Lun and Savage [25]:

$$
\lambda_{s}=\frac{4}{3} \varepsilon_{s} \rho_{s} d_{s} g_{o, s s}\left(1+e_{s s}\right) \sqrt{\frac{\Theta_{s}}{\pi}} .
$$

The bulk viscosity of a fluid $\left(\lambda_{g}\right)$ is a measure of the difference between the thermodynamic and mechanical pressures, and, 
for a Newtonian fluid (e.g., air), the bulk viscosity is set to zero in what is referred to as Stokes' assumption [7, 9].

The granular temperature $(\Theta)$ of solid phase as an order of solid fluctuation is defined as one-third of the mean square velocity of particles random motion. A complete solution procedure of the granular temperature equation has not yet been developed. Jenkins and Mancini [26] have developed a theoretical description of a suspension with more than one particle size, employing the kinetic theory of granular flow. They predicted transport properties of binary mixture assuming equal granular temperature [9-12]. Gidaspow [1] and Huili et al. [12] have extended the kinetic theory of dense gases for binary granular mixture with unequal granular temperature between the particle phases. In this work, similar to some researches $[10,11,15-17]$ the following algebraic granular temperature equation was used with the assumptions that the granular energy is dissipated locally and the convection and diffusion contributions are negligible and retaining only the generation and dissipation terms. When using this algebraic equation instead of solving the balance for the granular temperature, much faster convergence is obtained during simulations:

$$
\Theta_{s}=\left\{\frac{-K_{1} \varepsilon_{s} \operatorname{tr}\left(\overline{\bar{D}}_{s}\right)+\sqrt{K_{1}^{2} \operatorname{tr}^{2}\left(\overline{\bar{D}}_{s}\right) \varepsilon_{s}^{2}+4 K_{4} \varepsilon_{s}\left[K_{2} \operatorname{tr}^{2}\left(\overline{\bar{D}}_{s}\right)+2 K_{s} \operatorname{tr}\left(\overline{\bar{D}}_{s}^{2}\right)\right]}}{2 \varepsilon_{s} K_{4}}\right\}^{2},
$$

where $\overline{\overline{D_{s}}}$ is the solids strain rate tensor,

$$
\begin{aligned}
\overline{\bar{D}}_{s}= & \frac{1}{2}\left[\nabla \vec{v}_{s}+\left(\nabla \vec{v}_{s}\right)^{T}\right], \\
K_{1}= & 2\left(1+e_{s s}\right) \rho_{s} g_{0, s s}, \\
K_{2}= & \frac{4}{3 \sqrt{\pi}} d_{s} \rho_{s}\left(1+e_{s s}\right) \varepsilon_{s} g_{0, s s}-\frac{2}{3} K_{3}, \\
K_{3}= & \frac{d_{s} \rho_{s}}{2}\left\{\frac{\sqrt{\pi}}{3\left(3-e_{s s}\right)}\left[1+0.4\left(1+e_{s s}\right)\left(3 e_{s s}-1\right) \varepsilon_{s} g_{0, s s}\right]\right. \\
& \left.\quad+\frac{8 \varepsilon_{s} g_{0, s s}\left(1+e_{s s}\right)}{5 \sqrt{\pi}}\right\} \\
K_{4}= & \frac{12\left(1-e_{s s}^{2}\right) \rho_{s} g_{0, s s}}{d_{s} \sqrt{\pi}} .
\end{aligned}
$$

For granular flows a solids pressure is calculated independently and used for the pressure gradient term, $p_{s}$, in the granular-phase momentum equation. Because a Maxwellian velocity distribution is used for the particles, a granular temperature is introduced into the model and appears in the expression for the solids pressure and viscosities [5, 7, 2325]. The solids pressure is composed of a kinetic term and a second term due to particle collisions (where $e_{s s}$ is the coefficient of restitution for particle collisions):

$$
p_{s}=\varepsilon_{s} \rho_{s} \Theta_{s}+2 \rho_{s}\left(1+e_{s s}\right) \varepsilon_{s}^{2} g_{o, s s} \Theta_{s}
$$

The collisional and kinetic parts and the optional frictional part are added to give the solids shear viscosity: $\mu_{s}=\mu_{s, \text { col }}+$ $\mu_{s, \text { kin }}+\mu_{s, \mathrm{fr}}$.

The collisional part of the shear viscosity is modeled as

$$
\mu_{s, \mathrm{col}}=\frac{4}{5} \varepsilon_{s} \rho_{s} d_{s} g_{o, s s}\left(1+e_{s s}\right)\left(\frac{\Theta_{s}}{\pi}\right)^{1 / 2} .
$$

The kinetic term is expressed in the Syamlal-O'Brien model as $[7,23,27]$ :

$$
\mu_{s, \mathrm{kin}}=\frac{\varepsilon_{s} \rho_{s} d_{s} \sqrt{\Theta_{s} \pi}}{6\left(3-e_{s s}\right)}\left[1+\frac{2}{5}\left(1+e_{s s}\right)\left(3 e_{s s}-1\right) \varepsilon_{s} g_{o, s s}\right] .
$$

Friction stress, which plays a significant role when the solidphase volume fraction gets close to the packing limit [23$25,28-32]$ is expressed by

$$
\mu_{s, \mathrm{fr}}=\frac{p_{s} \sin \Phi}{2 \sqrt{I_{2 D}}},
$$

where $p_{s}$ is the solids pressure, $\phi$ is the angle of internal friction, and $I_{2 D}$ is the second invariant of the deviatoric stress tensor. The diffusion coefficient for granular energy, $k_{\Theta_{s}}$, is expressed by two different models. The SyamlalO'Brien model is expressed as $[23,24]$

$$
\begin{aligned}
& k_{\Theta_{s}}= \frac{15 d_{s} \rho_{s} \varepsilon_{s} \sqrt{\pi \Theta_{s}}}{4(41-33 \eta)} \\
& \times\left[1+\frac{12}{5} \eta^{2}(4 \eta-3) \varepsilon_{s} g_{o, s s}+\frac{16}{15 \pi}(41-33 \eta) \eta \varepsilon_{s} g_{o, s s}\right], \\
& \eta=\frac{1}{2}\left(1+e_{s s}\right) .
\end{aligned}
$$

3.2. Initial and Boundary Conditions. The initial values of the variables for all the fields $\left(\varepsilon_{g}, \varepsilon_{s}, v_{g}\right.$, and $\left.v_{s}\right)$ are specified for the entire computational domain. Initially, solid particle velocity was set at zero (in minimum fluidization), and gas velocity was assumed to have the same value everywhere in the bed. At the inlet, all velocities and volume fraction of all phases were specified. Outlet boundary condition was outflow and was assumed to be a fully developed flow. The other variables were subject to the Neumann boundary condition. At the wall, the gas tangential normal velocities were set to zero (no slip condition). The following boundary 
equations were applied for the tangential velocity of particle on the wall and for granular temperature at the wall $[3,4,10$, 11, 19-22, 25]:

$$
\begin{gathered}
\vec{v}_{s, w}=-\frac{6 \mu_{s} \varepsilon_{s, \max }}{\sqrt{3} \pi \phi \rho_{s} \varepsilon_{s} g_{o, s s} \sqrt{\Theta_{s}}} \frac{\partial \vec{v}_{s, w}}{\partial n}, \\
\Theta_{s, w}=-\frac{k_{s} \Theta_{s}}{e_{s s, w}} \frac{\partial \Theta_{s, w}}{\partial n}+\frac{\sqrt{3} \pi \rho_{s} \varepsilon_{s} v_{s}^{2} g_{o} \Theta_{s}^{3 / 2}}{6 \varepsilon_{s, \max } e_{s s, w}} .
\end{gathered}
$$

Here $\vec{v}_{s, w}$ is the particle slip velocity, $e_{s s, w}$ is the restitution coefficient at the wall, and $\varepsilon_{s, \max }$ is the volume fraction for the particles at maximum packing [19-25, 27].

3.3. Model Solution Procedure. Two-dimensional (2D) simulations of the fluidized bed under steady conditions were performed, and the results are described in this section. The Eulerian multiphase model described earlier was used for the analysis. The $2 \mathrm{D}$ computational domain was discretized using 8600 rectangular cells. Typically, a time step of $0.001 \mathrm{~s}$ with 20 iterations per time step was also used. This number of iterations was found to be adequate to achieve convergence for the majority of time steps. Table 1 shows values of model parameters that were used in the simulations. The discretized governing equations were solved by the finite volume method employing the Semiimplicit Method for the Pressure-Linked Equations (SIMPLE) algorithm that was developed by Patankar and Spalding [4] for multiphase flow using the Partial Elimination Algorithm (PEA). Several research groups $[10,11,23-26,33-36]$ have used extensions of the SIMPLE method, which appears to be the method of choice in commercial CFD codes [7, 9-11]. In this study, the second-order discretization schemes at time step of $0.001 \mathrm{~s}$ with $10^{-3}$ convergence criterion were used in numerical procedure.

\section{Results and Discussion}

Simulation results were compared with the experimental data in order to validate the model. Pressure drop was measured experimentally for different superficial gas velocities for three particle sizes and compared with those predicted by CFD simulation. As indicated in Figure 2, the bed overall pressure drop $(P 1-P 3)$ decreased significantly at the beginning of fluidization and then fluctuated around a near steady-state value after about $4 \mathrm{~s}$. After this time, the fluctuations of pressure decrease. The pressure drop fluctuations that are expected as bubbles in the fluidized bed continuously form, split, and coalesce in a transient manner in the fluidized bed. The results show that, with increasing the particles size, pressure drop, increases. Comparison of the model predictions, using the Syamlal-O'Brien drag functions and experimental measurements on pressure drop, indicated good agreement for most operating conditions.

Comparison of experimental and simulated bed pressure drops (pressure difference between two positions, P1-P2 and $P 1-P 3)$ for two different particle sizes, $d_{s}=0.175 \mathrm{~mm}$ and $d_{s}=0.375 \mathrm{~mm}$, at different superficial gas velocities is shown in Figure 3. Pressure transducers positions ( $P 1$,
TABLE 1: Values of model parameters used in the simulations and

\begin{tabular}{|c|c|c|c|}
\hline Symbol & Description & Value & $\begin{array}{l}\text { Comment or } \\
\text { reference }\end{array}$ \\
\hline$\rho_{s}$ & Solids density & $1883 \mathrm{~kg} / \mathrm{m}^{3}$ & $\begin{array}{l}\text { A special type of Glass } \\
\text { beads }\end{array}$ \\
\hline$\rho_{g}$ & Gas density & $1.225 \mathrm{~kg} / \mathrm{m}^{3}$ & $\begin{array}{l}\text { Air at ambient } \\
\text { conditions }\end{array}$ \\
\hline$d_{s}$ & $\begin{array}{l}\text { Mean particle } \\
\text { diameter }\end{array}$ & $\begin{array}{l}175,275 \\
375 \mu \mathrm{m}\end{array}$ & Three size of particle \\
\hline$e_{s s}$ & $\begin{array}{l}\text { Coefficient of } \\
\text { restitution }\end{array}$ & 0.85 & Fixed value \\
\hline$\varepsilon_{s, \max }$ & $\begin{array}{l}\text { Maximum } \\
\text { solids packing }\end{array}$ & 0.64 & $\begin{array}{c}\text { Syamlal and O'Brien } \\
{[23,24]}\end{array}$ \\
\hline$\phi$ & $\begin{array}{c}\text { Angle of } \\
\text { internal friction }\end{array}$ & $27^{\circ}$ & $\begin{array}{c}\text { Johnson and Jackson } \\
\text { [33] }\end{array}$ \\
\hline$D_{t}$ & $\begin{array}{l}\text { Column } \\
\text { diameter }\end{array}$ & $28 \mathrm{~cm}$ & Fixed value \\
\hline$H_{1}$ & $\begin{array}{l}\text { Fluidized bed } \\
\text { height }\end{array}$ & $100 \mathrm{~cm}$ & Fixed value \\
\hline$H_{0}$ & $\begin{array}{c}\text { Initial static bed } \\
\text { height }\end{array}$ & $44 \mathrm{~cm}$ & Fixed value \\
\hline$U_{g}$ & $\begin{array}{l}\text { Superficial gas } \\
\text { velocity }\end{array}$ & $0-100 \mathrm{~cm} / \mathrm{s}$ & A range is used \\
\hline
\end{tabular}
experiments.

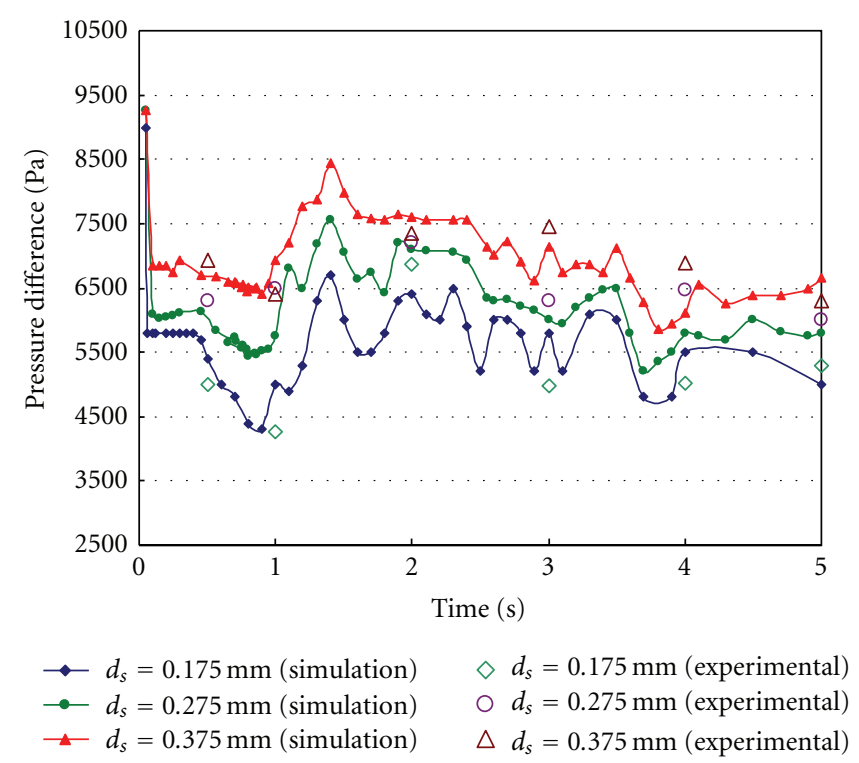

Figure 2: Comparison of experimental and simulation bed pressure drops $(P 1-P 3)$ with different solid particle sizes.

$P 2$, and P3) also were shown in Figure 1. The simulation and experimental results show better agreement at velocities above $U_{\mathrm{mf}}$. The discrepancy for $U<U_{\mathrm{mf}}$ may be attributed to the solids not being fluidized, thus being dominated by interparticle frictional forces, which are not predicted by the multifluid model for simulating gas-solid phases. This figure shows that, with increasing gas velocity, initially the pressure drops $(P 1-P 2$ and $P 1-P 3)$ increase, but the rate of increase for $P 1-P 3$ is larger than for $P 1-P 2$. For $U>U_{\mathrm{mf}}$ this figure shows 


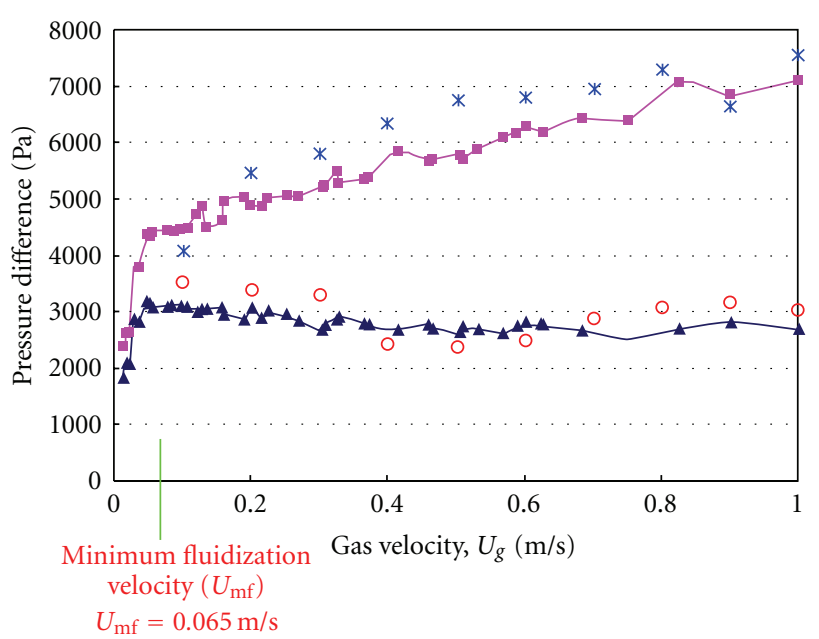

$\begin{array}{ll}\leftarrow P 1-P 2 \text { (simulation) } & * P 1-P 2 \text { (experimental) } \\ \rightarrow-P 1-P 3 \text { (simulation) } & \circ P 1-P 3 \text { (experimental) }\end{array}$

Figure 3: Comparison of experimental and simulated bed pressure drops at different superficial gas velocities $\left(d_{s}=0.275 \mathrm{~mm}\right)$.

that $P 1-P 3$ increases with gas velocity, while $P 1-P 2$ decreases slightly, stays roughly constant, and increases slightly. This trend is perhaps due to the expansion of the bed and the decrease in the amount of solids between ports 1 and 2 . As the gas velocity increases further, the wall shear stress increases and the pressure drop begins to increase. Ports 1 and 3 cover the entire height of the dense bed in the column, and thus P1-P3 increases with gas velocity. The results show that, with increasing the particle size and gas velocity, pressure drop (P1-P2 and $P 1-P 3)$ increases. Comparison of the model predictions and experimental measurements on pressure drop (for both cases) shows good agreement at different gas velocities.

Figure 4 compares experimental results for bubble formation and bed expansion for different superficial gas velocities. At low gas velocities, the solids rest on the gas distributor and the column is in the fixed bed regime. When superficial gas velocity reaches the fluidization velocity, all particles are suspended by upward flowing gas and the bed is fluidized. Also, the bubbles are formed in the beds that are moved to the upper part of the column. With increase in the gas velocity, the intensity of bubble formation and collapse increases sharply. The experiments indicated small bubbles near the bottom of the bed; the bubbles grow as they rise to the top surface with coalescence. The elongation of the bubbles is due to wall effects and interaction with other bubbles. This in turn leads to an increase in the pressure drop as shown in Figure 3. The simulation results of time-average crosssectional void fraction at different solid particles diameters is shown in Figure 5 for $U_{g}=38 \mathrm{~cm} / \mathrm{s}$. This figure shows that, with increasing solid particles diameter, void fraction decreases and maximum of void fraction reaches a lower height of dryer.

Simulation results for void fraction profile are shown in Figure 6. In this figure symmetry of the void fraction

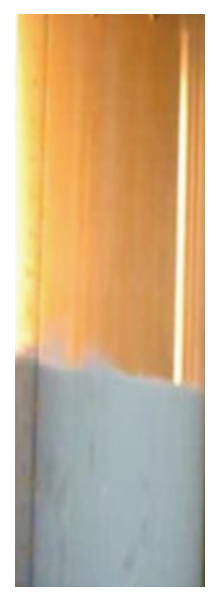

$U_{g}=0.1 \mathrm{~m} / \mathrm{s}$

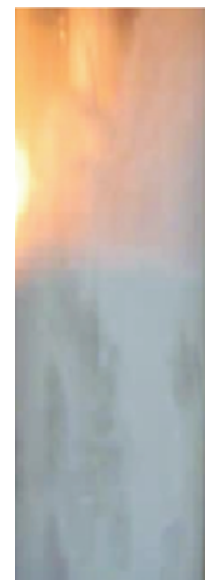

$U_{g}=0.6 \mathrm{~m} / \mathrm{s}$

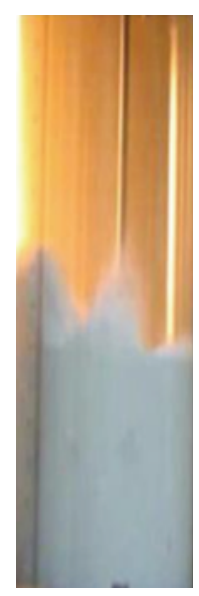

$U_{g}=0.2 \mathrm{~m} / \mathrm{s}$

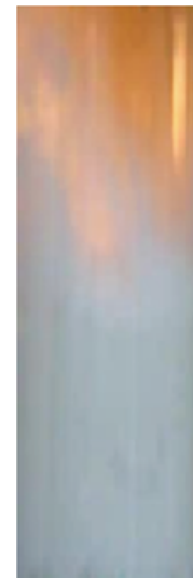

$U_{g}=0.7 \mathrm{~m} / \mathrm{s}$

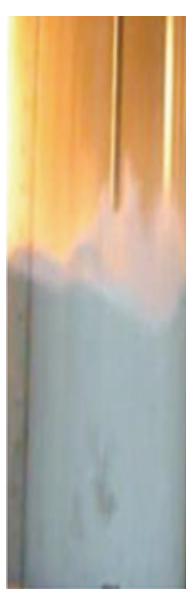

$U_{g}=0.4 \mathrm{~m} / \mathrm{s}$

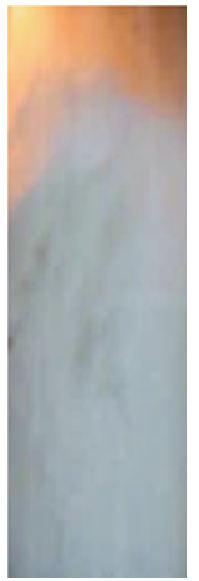

$U_{g}=0.8 \mathrm{~m} / \mathrm{s}$
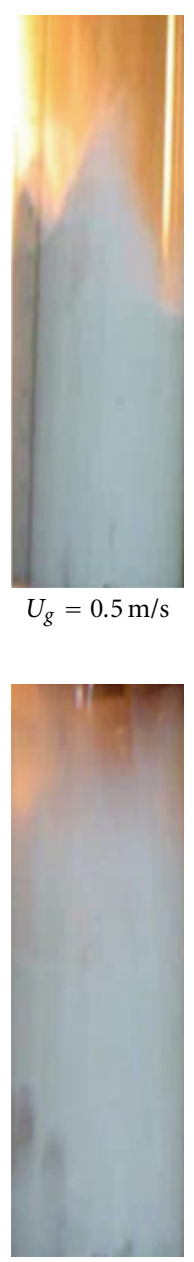

$U_{g}=1 \mathrm{~m} / \mathrm{s}$
FIgUre 4: Comparison of bubble formation and bed expansion for different superficial gas velocities.

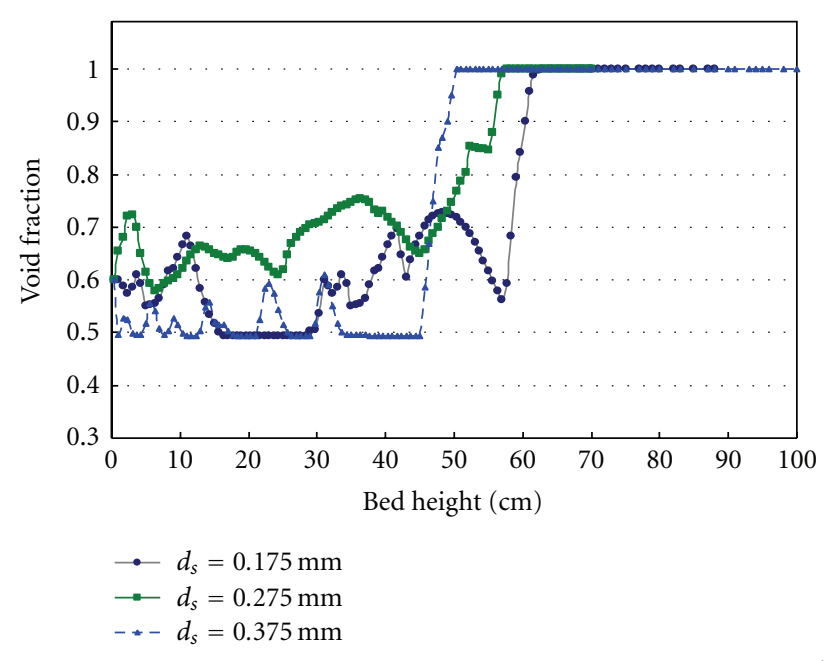

FIGURE 5: Simulation results of time-average cross-sectional void fraction at different solid particles diameters $\left(U_{g}=38 \mathrm{~cm} / \mathrm{s}\right)$. 


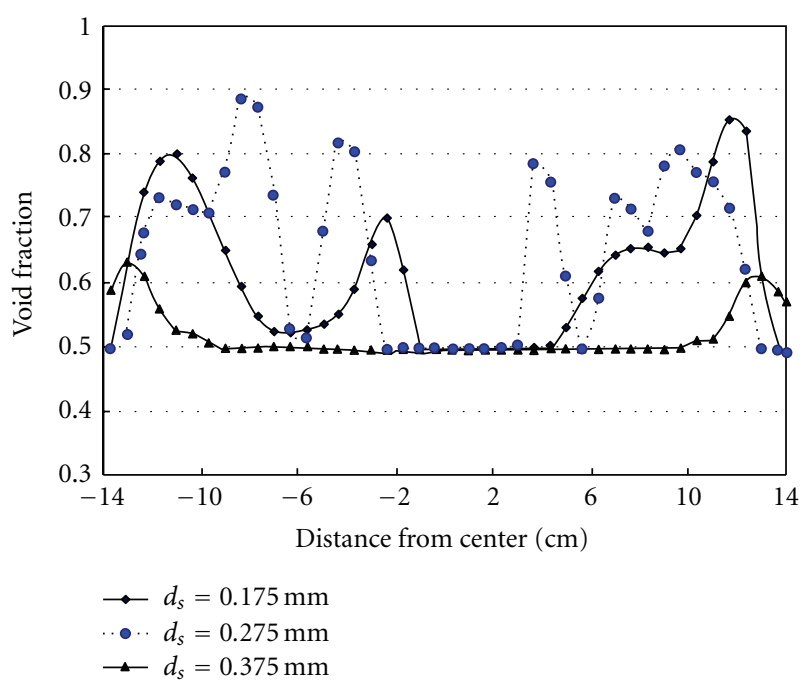

Figure 6: Simulated time-average void fraction with different solid particles diameters (at $z=20 \mathrm{~cm}, U_{g}=38 \mathrm{~cm} / \mathrm{s}$ ).

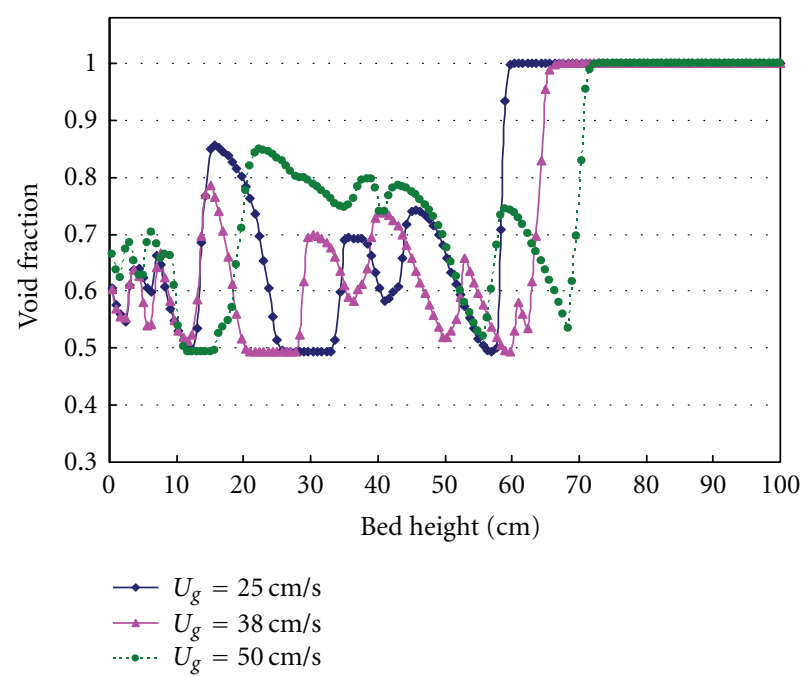

Figure 7: Simulation results of time-average void fraction at different superficial gas velocities $\left(d_{s}=0.275 \mathrm{~mm}\right)$.

is observed for three different particle sizes. The slight asymmetry in the void fraction profile may result from the development of a certain flow pattern in the bed. Similar asymmetry has been observed in other CFD modeling of fluidized beds $[7,10,11]$. Void fraction profile for large particle is flatter near the center of the bed. Figure 7 shows the simulation results of time-average cross-sectional void fraction at different superficial gas velocities. This figure shows that, with increasing superficial gas velocity, void fraction also increases. At the start of the simulation, waves of voidage are created, which travel through the bed and subsequently break to form bubbles as the simulation progresses.

At the bottom of the column, particle concentration is larger than at the upper part. Therefore, the maximum gas

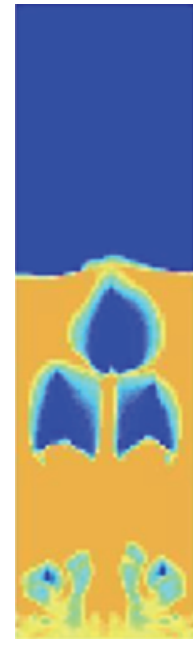

$t=1.5 \mathrm{~s}$
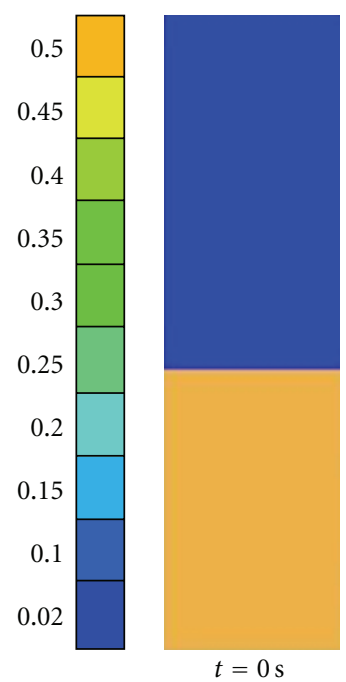

$t=2 \mathrm{~s}$
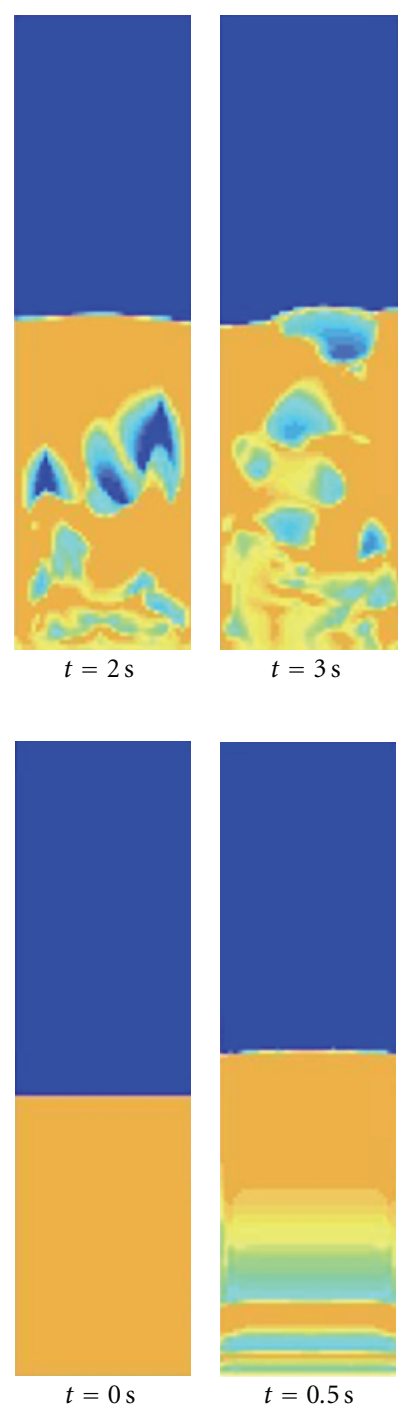

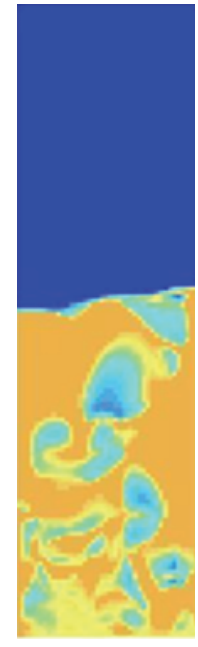

$t=4 \mathrm{~s}$

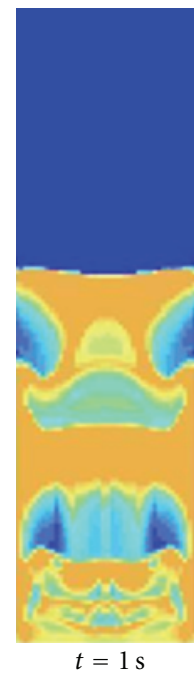

FIGURE 8: Simulated solids volume fraction profile of $2 \mathrm{D}$ bed $\left(U_{g}=\right.$ $\left.38 \mathrm{~cm} / \mathrm{s}, d_{s}=0.275 \mathrm{~mm}\right)$.

volume fraction occurs at the top of the column. Clearly the gas volume fraction of 1 (at the top of the bed) corresponds to the region where the particles are absent. With increasing superficial gas velocity, Figure 7 shows that the gas volume fraction generally increases in the bed and reaches 1 at the top of the bed. Gas volume fraction approaches the saturation condition of 1 at the bed heights of $58 \mathrm{~cm}, 63 \mathrm{~cm}$, and $68 \mathrm{~cm}$ for $U_{g}=25 \mathrm{~cm} / \mathrm{s}, 38 \mathrm{~cm} / \mathrm{s}$, and $50 \mathrm{~cm} / \mathrm{s}$, respectively. For higher gas velocities, Figure 7 shows that the gas volume fraction is larger at the same height in the bed because the amount of particles is constant and, for higher gas velocity, the bed height is higher. It should be noted here that the fluctuations of the curves in this figure are a result of bubble formation and collapse.

Figure 8 shows simulated results for contour plot of solids volume fraction $\left(U_{g}=38 \mathrm{~cm} / \mathrm{s}, d_{s}=0.275 \mathrm{~mm}\right)$. Initially, the bed height increased with bubble formation until it leveled off at a steady-state bed height. The observed 
axisymmetry gave way to chaotic transient generation of bubble formation after $3 \mathrm{~s}$. The results show that the bubbles at the bottom of the bed are relatively small. The bubbles coalesce as they move upwards producing bigger bubbles. The bubbles become stretched as a result of bed wall effects and interactions with other bubbles. The Syamlal-O'Brien drag model provided similar qualitative flow patterns. The sizes of the bubbles predicted by the CFD models are in general similar to those observed experimentally. Any discrepancy could be due to the effect of the gas distributor, which was not considered in the CFD modeling of fluid bed. In practice, jet penetration and hydrodynamics near the distributor are significantly affected by the distributor design.

The effect of numerical implementation including the time step, discretization schemes, mesh size, and convergence criterion on the results and sensitivity analysis was studied. The results show no noticeable difference in overall hydrodynamic behavior and bubble shapes among these simulations; therefore, it is concluded that the selected numerical parameters are adequate for proper simulations of bed hydrodynamics.

\section{Conclusion}

In this research, the hydrodynamics of two-dimensional nonreactive gas-solid fluidized bed dryer was investigated computationally and experimentally. Because of the preliminary investigation of multiphase flow models revealed that Eulerian-Eulerian model is suitable for modeling of industrial fluidized bed dryers. So, a multifluid Eulerian model incorporating the kinetic theory for solid particles was applied. Governing equations of the system were solved by finite volume method employing Semiimplicit Method for Pressure-Linked Equations (SIMPLE) algorithm, that is developed for multiphase flow using Partial Elimination Algorithm (PEA). The first-order upwind scheme was used for discretization of the equations.

Also, solid particles diameter and superficial gas velocity effects on hydrodynamics were studied. In order to validate the CFD model, simulation results were compared with the experimental data. Comparison of the model predictions, using the Syamlal-O'Brien drag functions and experimental measurements on pressure drop and the time-average bed indicated good agreement for most operating conditions. Simulation results also indicated that small bubbles were produced at the bottom of the bed. These bubbles collided with each other as they moved upwards forming larger bubbles. Furthermore this comparison showed that the model can predict hydrodynamic behavior of gas solid fluidized bed reasonably well.

\section{Acknowledgments}

The authors would like to express their gratitude to the Fluid Mechanics Research Center in Department of Mechanical Engineering of Amirkabir University and the Petrochemical Research and Technology Company for providing financial support for this study.

\section{References}

[1] D. Gidaspow, Multiphase Flow and Fluidization, Academic Press, London, UK, 1st edition, 1994.

[2] D. Kunii and O. Levenspiel, Fluidization Engineering, Butterworth-Heinemann, Boston, Mass, USA, 2nd edition, 1991.

[3] V. V. Ranade, Computational Flow Modeling for Chemical Dryer Engineering, Academic Press, New York, NY, USA, 1st edition, 2002.

[4] S. V. Patankar, Numerical Heat Transfer and Fluid Flow, Hemisphere Publishing, Washington, DC, USA, 1st edition, 1980.

[5] J. R. Grace and F. Taghipour, "Verification and validation of CFD models and dynamic similarity for fluidized beds," Powder Technology, vol. 139, no. 2, pp. 99-110, 2004.

[6] M. J. V. Goldschmidt, J. A. M. Kuipers, and W. P. M. van Swaaij, "Hydrodynamic modeling of dense gas fluidized beds using the kinetic theory of granular flow: effect of coefficient of restitution on bed dynamics," Chemical Engineering Science, vol. 56, pp. 571-578, 2001.

[7] F. Taghipour, N. Ellis, and C. Wong, "Experimental and computational study of gas-solid fluidized bed hydrodynamics," Chemical Engineering Science, vol. 60, no. 24, pp. 6857-6867, 2005.

[8] R. B. Bird, W. E. Stewart, and E. N. Lightfoot, Transport Phenomena, John Wiley \& Sons, New York, NY, USA, 2nd edition, 2002.

[9] Y. Kaneko, T. Shiojima, and M. Horio, "DEM simulation of fluidized beds for gas-phase olefin polymerization," Chemical Engineering Science, vol. 54, no. 24, pp. 5809-5821, 1999.

[10] Y. Behjat, S. Shahhosseini, and S. H. Hashemabadi, "CFD modeling of hydrodynamic and heat transfer in fluidized bed dryers," International Communications in Heat and Mass Transfer, vol. 35, pp. 357-368, 2008.

[11] F. Rong, D. L. Marchisio, and R. O. Fox, "CFD Simulation of Polydisperse Fluidized-Bed Polymerization Dryers," Department of Chemical Engineering, Iowa State University, Sweeney Hall, Ames, IA , USA, Preprint submitted to Elsevier Science, August 2003.

[12] L. U. Huilin, H. E. Yurong, and D. Gidaspow, "Hydrodynamic modelling of binary mixture in a gas bubbling fluidized bed using the kinetic theory of granular flow," Chemical Engineering Science, vol. 58, no. 7, pp. 1197-1205, 2003.

[13] LU. Huilin, L. Wentie, LI. Feng, Z. Guangbo, and HE. Yurong, "Eulerian simulations of bubble behaviour in a twodimensional gas-solid bubbling fluidized bed," International Journal of Energy Research, vol. 26, no. 15, pp. 1285-1293, 2002.

[14] A. Gobin, H. Neau, O. Simonin, J. R. Llinas, V. Reiling, and J. L. Sélo, "Fluid dynamic numerical simulation of a gas phase polymerization reactor," International Journal for Numerical Methods in Fluids, vol. 43, no. 10-11, pp. 1199-1220, 2003.

[15] B. G. M. Van Wachem, J. C. Schouten, C. M. Van den Bleek, R. Krishna, and J. L. Sinclair, "Comparative analysis of CFD models of dense gas-solid systems," AIChE Journal, vol. 47, no. 5, pp. 1035-1051, 2001.

[16] B. G. M. Van Wachem, J. C. Schouten, C. M. Van den Bleek, R. Krishna, and J. L. Sinclair, "CFD modeling of gas-fluidized beds with a bimodal particle mixture," AIChE Journal, vol. 47, no. 6, pp. 1292-1302, 2001.

[17] B. G.M. Van Wachem, J. C. Schouten, R. Krishna, and C. M. Van Den Bleek, "Eulerian simulations of bubbling behaviour 
in gas-solid fluidised beds," Computers and Chemical Engineering, vol. 22, supplement 1, pp. S299-S306, 1998.

[18] M. Chiesa, V. Mathiesen, J. A. Melheim, and B. Halvorsen, "Numerical simulation of particulate flow by the EulerianLagrangian and the Eulerian-Eulerian approach with application to a fluidized bed," Computers and Chemical Engineering, vol. 29, no. 2, pp. 291-304, 2005.

[19] M. Hamzehei and H. Rahimzadeh, "Numerical and experimental investigation of a fluidized bed chamber hydrodynamics with heat transfer," Korean Journal of Chemical Engineering, vol. 27, no. 1, pp. 355-363, 2010.

[20] M. Hamzehei, H. Rahimzadeh, and G. Ahmadi, "Computational and experimental study of heat transfer and hydrodynamics in a 2D gas-solid fluidized bed reactor," Industrial and Engineering Chemistry Research, vol. 49, no. 11, pp. 5110-5121, 2010.

[21] M. Hamzehei and H. Rahimzadeh, "Experimental and numerical study of hydrodynamics with heat transfer in a gas-solid fluidized-bed reactor at different particle sizes," Industrial and Engineering Chemistry Research, vol. 48, no. 6, pp. 3177-3186, 2009.

[22] M. Hamzehei, H. Rahimzadeh, and G. Ahmadi, "Studies of gas velocity and particles size effects on fluidized bed hydrodynamics with CFD modeling and experimental investigation," Journal of Mechanics, vol. 26, pp. 113-124, 2010.

[23] M. Syamlal and T. J. O'Brien, "Computer simulation of bubbles in a fluidized bed," A.I.Ch.E. Symposium Series, vol. 85 , pp. 22-31, 1989.

[24] M. Syamlal and T. J. O’Brien, "Fluid Dynamic Simulation of O Decomposition in a Bubbling Fluidized Bed," AIChE Journal, vol. 49, no. 11, pp. 2793-2801, 2003.

[25] C. K. K. Lun and S. B. Savage, "A simple kinetic theory for granular flow of rough, inelastic, spherical particles," Journal of Applied Mechanics, vol. 54, pp. 47-53, 1987.

[26] M. Syamlal, "MFIX documentation: numerical techniques," Tech. Rep. DOE/MC-31346-5824. NTIS/DE98002029, National Technical Information Service, Springfield, Va, USA, 1998.

[27] I. K. Gamwo, Y. Soong, and R. W. Lyczkowski, "Numerical simulation and experimental validation of solids flows in a bubbling fluidized bed," Powder Technology, vol. 103, no. 2, pp. 117-129, 1999.

[28] M. Hamzehei and H. Rahimzadeh, "Study of parameters effect on hydrodynamics of a gas-solid chamber experimentally and numerically," in Proceeding of Experimental Fluid Mechanics Conference (EFM '10), Liberec, Czech Republic, November 2010.

[29] M. Hamzehei, H. Rahimzadeh, and G. Ahmadi, "CFD modeling and simulation of hydrodynamics in a fluidized bed chamber with experimental validation," in Proceeding of the 31st IASTED International Conference on Modelling, Identification, and Control (MIC '11), Innsbruck, Austria, February 2011.

[30] M. Hamzehei and H. Rahimzadeh, "Study of particle size effects on hydrodynamics of a fluidized bed chamber experimentally and computationally," in Proceedings of the $3 \mathrm{rd}$ Technology and Innovation for Sustainable conference (TISD '10), Nong Khai, Thailand, March 2010.

[31] M. Hamzehei and H. Rahimzadeh, "Study of hydrodynamics in a two phase fluidized bed reactor experimentally and numerically," in Proceedings of the 7th South African Conference on Computational and Applied Mechanics (SACAM '10), Pretoria, January 2010.

[32] M. Hamzehei, Heat Transfer-Mathematical Modelling, Numerical Methods and Information Technology, Study of
Hydrodynamics and Heat Transfer in the Fluidized Bed Reactors, chapter 14, InTech Publication, 2011.

[33] P. C. Johnson and R. Jackson, "Frictional-collisional constitutive relations for granular materials, with application to plane shearing," Journal of Fluid Mechanics, vol. 176, pp. 67-93, 1987.

[34] K. Hui, P. K. Haff, J. E. Ungar, and R. Jackson, "Boundary conditions for high-shear grain flows," Journal of Fluid Mechanics, vol. 145, pp. 223-233, 1984.

[35] M. Syamlal, W. A. Rogers, and T. J. O’Brien, "MFIX documentation, theory guide," Tech. Rep. DOE/METC-94/1004, NTIS/DE94000087, National Technical Information Service, Springfield, Va, USA, 1993.

[36] M. Hamzehei, H. Rahimzadeh, and G. Ahmadi, "Study of heat transfer and hydrodynamics in a gas-solid fluidized bed reactor experimentally and numerically," in Proceedings of the International Conference on Mechanical and Aerospace Engineering (CMAE '11), New Delhi, India, March 2011. 

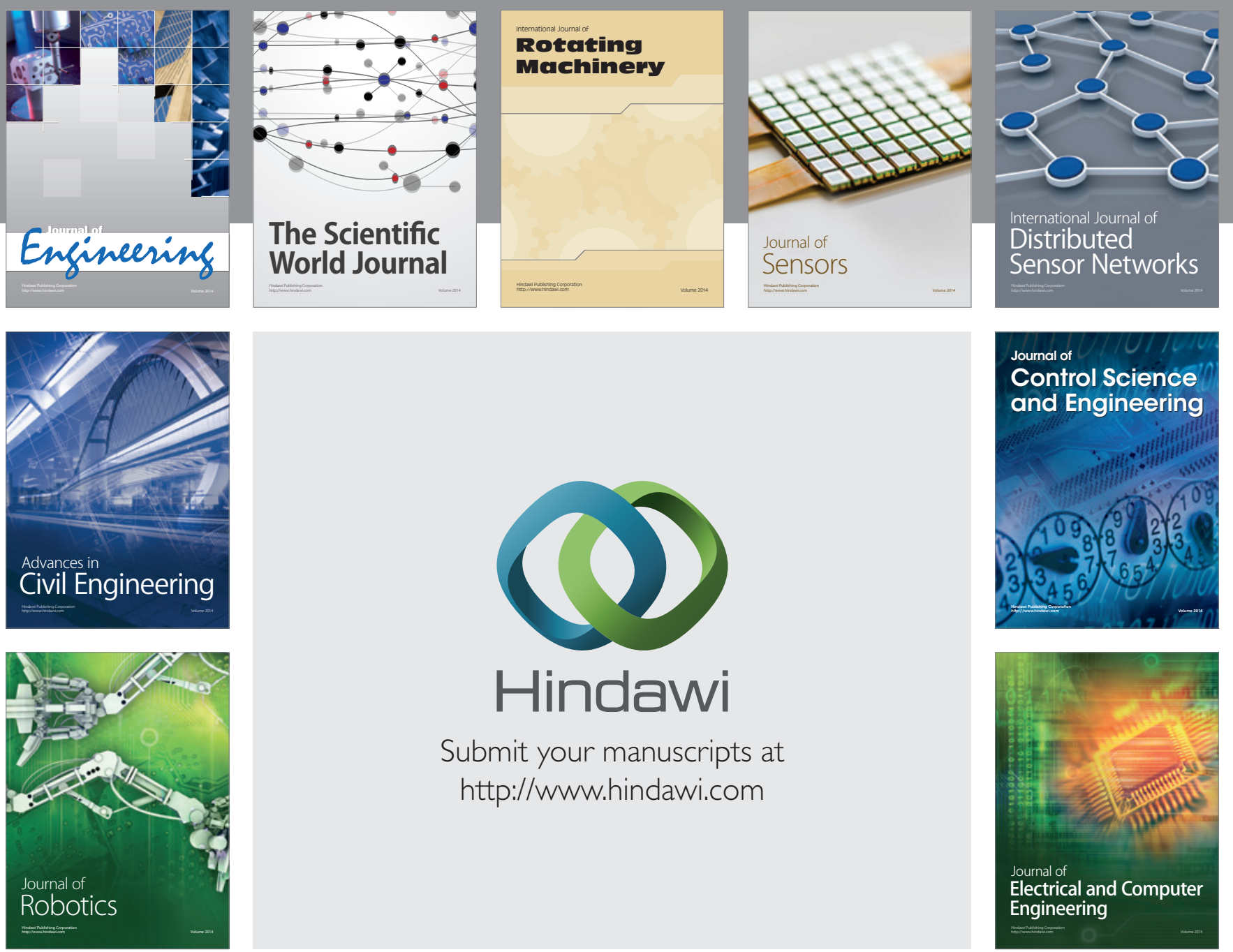

Submit your manuscripts at

http://www.hindawi.com
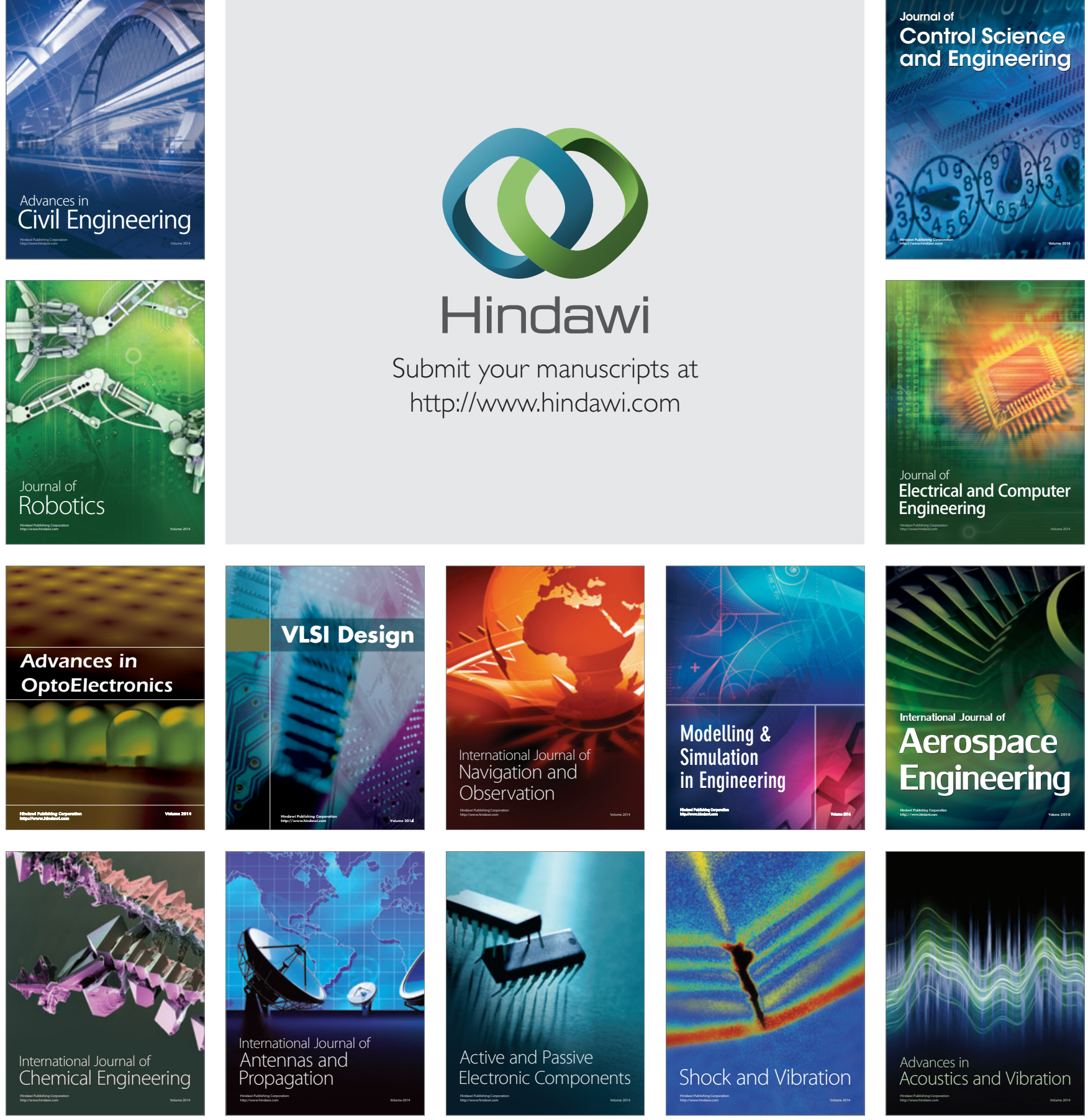